\title{
Dynamic properties of façade frame scaffoldings
}

\author{
Jarosław Bęc ${ }^{1, *}$, and Ewa Błazik-Borowa ${ }^{1}$ \\ ${ }^{1}$ Lublin University of Technology, Faculty of Civil Engineering and Architecture, Nadbystrzycka 40, \\ 20-618 Lublin, Poland
}

\begin{abstract}
The paper presents data on natural frequencies and damping parameters of scaffoldings. The analyzes were made mainly on the basis of acceleration measurements made on scaffoldings on construction sites. These studies were supplemented by numerical analyzes, which allowed to show changing of the natural frequencies of the scaffoldings as the effect of the structure exploitation. Finally, it was found that the scaffoldings are structures with low natural frequencies ranging from $1.0 \mathrm{~Hz}$ to $4.0 \mathrm{~Hz}$ and a logarithmic decrement of damping at 0.06 in most cases, however differences can be observed with the values as low as 0.03 .
\end{abstract}

\section{Introduction}

Scaffoldings are rod structures, stiffened with use of decks. Principles of operation of scaffoldings as a frame system under the influence of static loads have been described in [1]. In this work, it was also shown that dynamic actions are a significant load for scaffolding. Performing dynamic analyzes requires examination of the dynamic properties of the scaffolding, in particular the damping parameters, the natural frequencies and the accompanying mode shapes of vibrations. In this paper there were used the results of research of 120 scaffoldings, which was carried out in the years 2016-2018 as a part of the PBS3/A2/19/2015 project "Modelling of Risk Assessment of Construction Disasters, Accidents, and Dangerous Incidents at Workplaces Using Scaffoldings" ORKWIZ, financed by the Polish National Center for Research and Development. As part of this project, among others, such tests as scaffolding and damage inventory (comp. [2], [3]), measurements of environmental parameters (comp. [4], [5]), loads measurements (comp. [1], [6], [7]), parameters of the work environment (comp. [8]) and measurements of accelerations of scaffolding vibrations (comp [1], [9]) were made. Based on measurements of scaffolding accelerations, frequencies of free vibrations were determined. For selected scaffoldings, damping parameters were calculated, and the problem of users' mass impact on the dynamic behavior of scaffolding was discussed. The methodology of the research is presented here on the example of scaffolding, marked with the symbol W09 in the ORKWIZ project.

\footnotetext{
*Corresponding author: j.bec@pollub.pl
} 


\section{Description of research methods}

\subsection{Measurements of accelerations of scaffolding vibrations}

Measurements of vibrations accelerations in selected points of scaffolding were made using Brüel \& Kjær measuring system. In most tests two uniaxial accelerometers and two triaxial accelerometers were used. Accelerometers were placed on top-level frames. The arrangement of the accelerometers is presented in Fig. 1 and the accelerometer mounted on the scaffolding frame is shown in Fig. 2a. The excitation was generated by one person, causing horizontal oscillations along the scaffolding, in the direction perpendicular to the scaffolding plane and bouncing vertically. The measurement frequency was $8192 \mathrm{~Hz}$. The excitations were implemented below the highest level of decks in three locations, also shown in Fig.1.

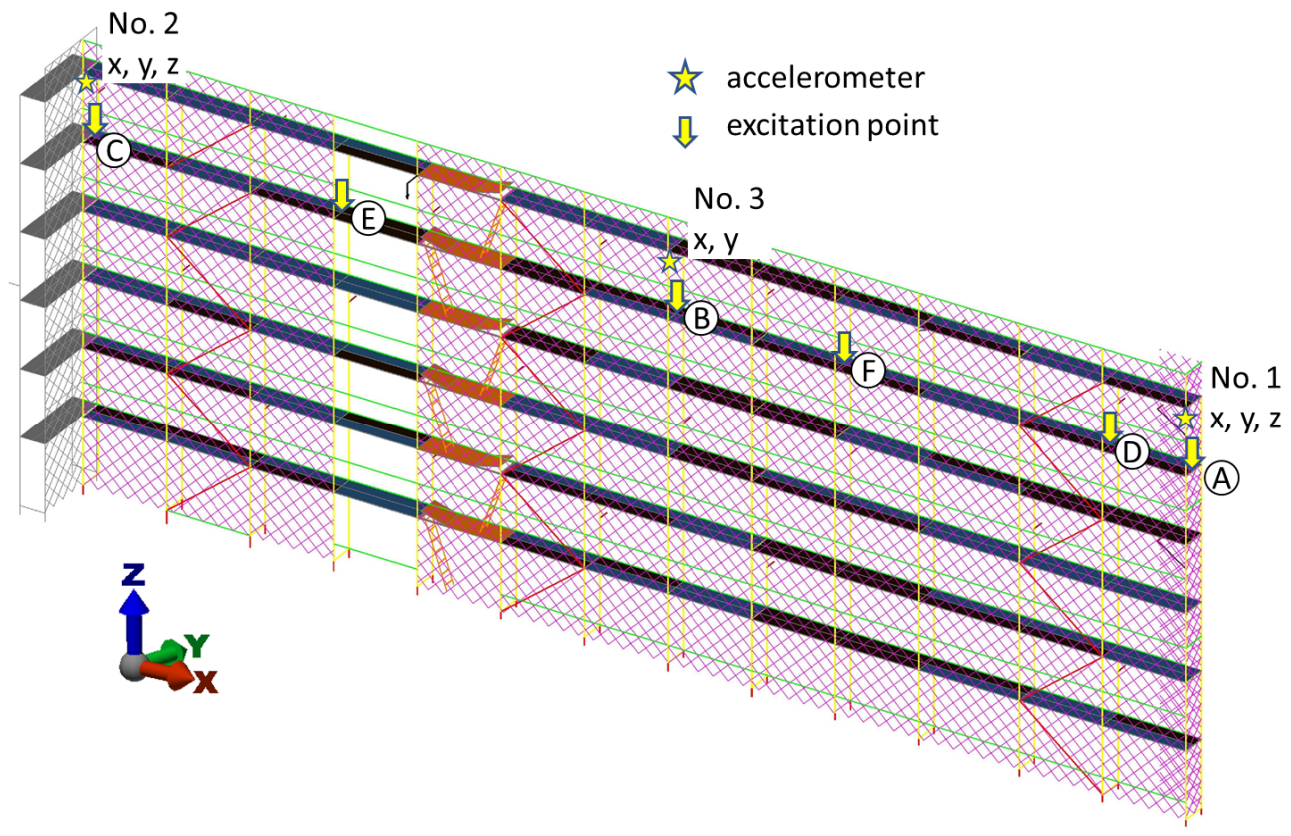

Fig.1. Scheme of the scaffolding with the locations of measurement and excitation points

\subsection{Analysis of measured signals}

The frequencies of free vibrations and scaffolding damping parameters were determined based on the measured time series of accelerations. For each of the measured signals, an FFT (Fast Fourier Transform) analysis was performed. Based on these results, the frequencies of free vibrations were determined.

The determination of damping parameters was limited to the determination of the logarithmic decrement of damping. The signals were filtered using Butterworth digital filter of the order 8. In the case of the results shown in Fig. $2 \mathrm{~b}$, a filter with a bandwidth of 1.5 $\mathrm{Hz}$ to $2.5 \mathrm{~Hz}$ was used and the analyzed frequency of free vibrations was $f_{s}=2 \mathrm{~Hz}$. As a result of the filtering, the waveforms shown in Fig. 2c were obtained. A fragment of 
vibrations with damping was selected from the filtered time series and local maxima were determined for this fragment. Then the points locations were approximated by a curve with the equation:

$$
y_{a}=A e^{-\gamma t},
$$

where: $\gamma$-damping coefficient.

Logarithmic decrement of damping is calculated with the formula:

$$
\Delta=\frac{\gamma}{\omega_{s}},
$$

where: $\omega_{s}=2 \pi f_{s}-$ circular frequency of free vibrations, $\gamma$ - damping coefficient.

a)

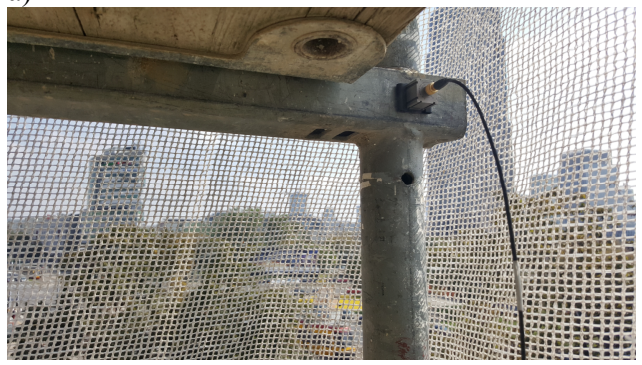

c)

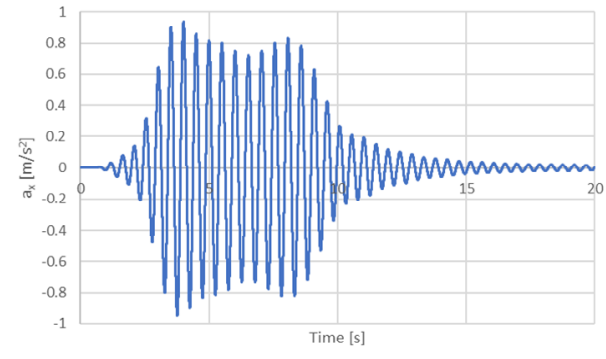

b)

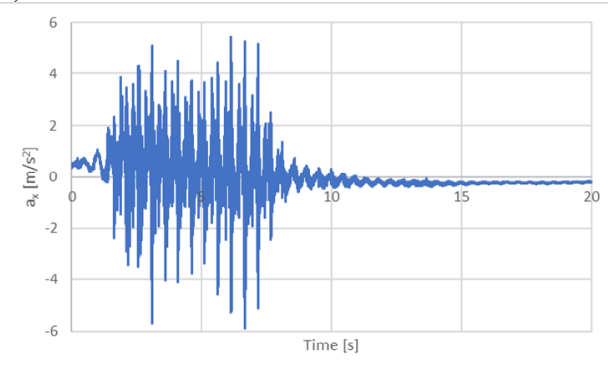

d)

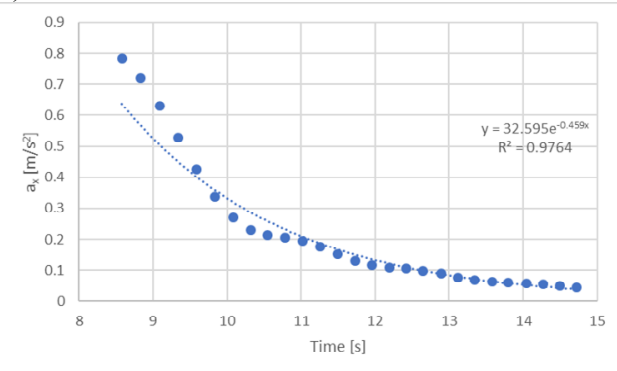

Fig.2. Determination of the damping coefficient: a) accelerometer mounted at the scaffolding frame b) fragment of the time series, c) fragment of the time series after filtration, d) curve fitted to the maxima of accelerations

\subsection{Numerical model of the scaffolding}

The last method of research presented here is numerical analysis of W09 scaffolding. The model considers the state of the structure and the effects of the scaffolding exploitation, for example the loosening of anchors in the wall ([1], [10]). This was achieved by calibrating the numerical model based on measurements of the free vibrations' frequencies. Figure 3 presents the model. The structure of the scaffolding was modeled with beam elements, while the decks - with shell elements. Connections between handrails and stands, braces and stands are modeled as hinge joints. The other connections are stiff. Supports, modeling the foundation on the ground and anchors in the wall, are modeled using hinged supports. 

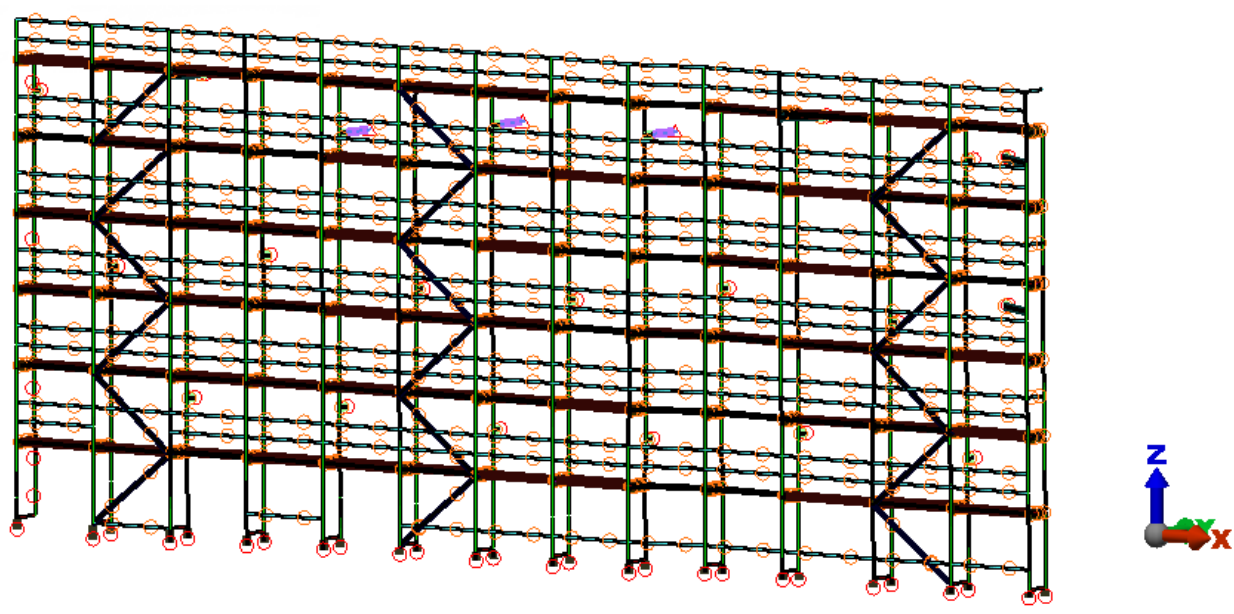

Fig. 3. Static scheme of the scaffolding

\section{Analysis of the results}

\subsection{Frequencies of free vibrations and natural frequencies}

For 120 scaffoldings analyzed in the ORKWIZ project, numerical models were made. The models were verified on the basis of acceleration measurements. Next, dynamic analyzes were performed for each of the scaffoldings, which resulted in natural frequencies and mode shapes. Fig. 4 shows, how the values of the first and second scaffolding natural frequency is distributed, without taking into account the additional mass of users. The first mode shape for 100 scaffoldings was observed as vibrations along the scaffolding plane. For 40 of the scaffoldings the second mode shape was also longitudinal. Fig. 5 shows the first four mode shapes of the W09 scaffolding.

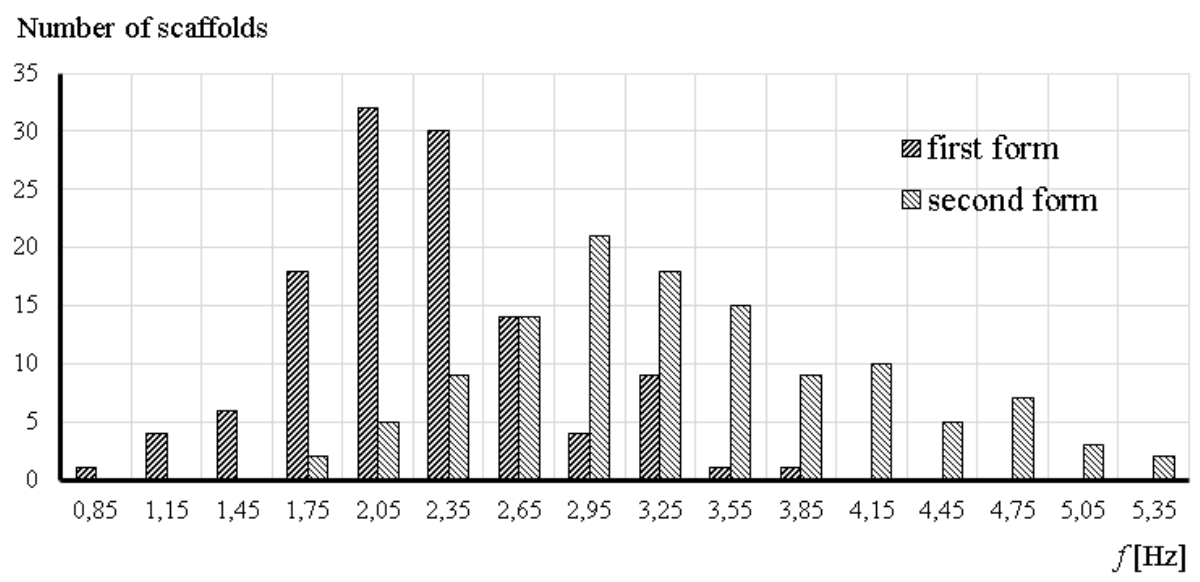

Fig. 4. The distribution of the values of the first two natural frequencies 
a)

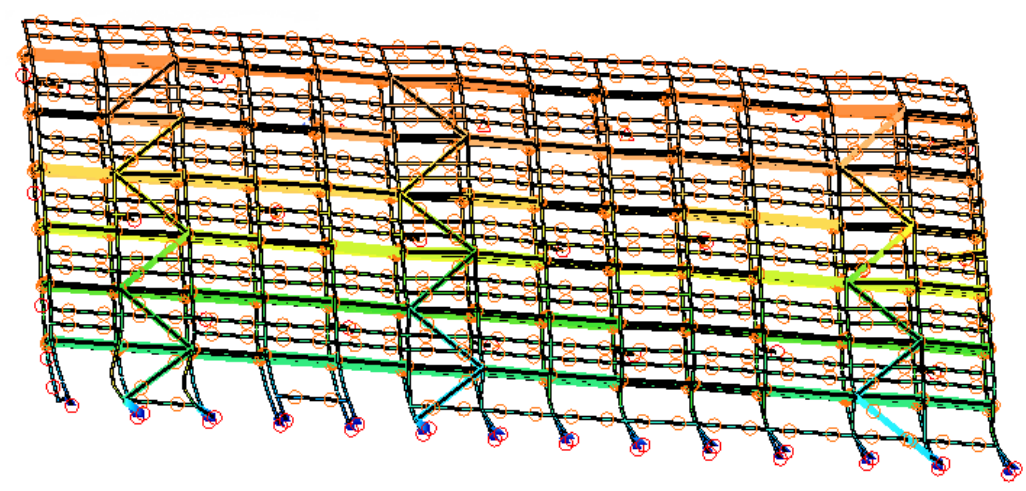

b)

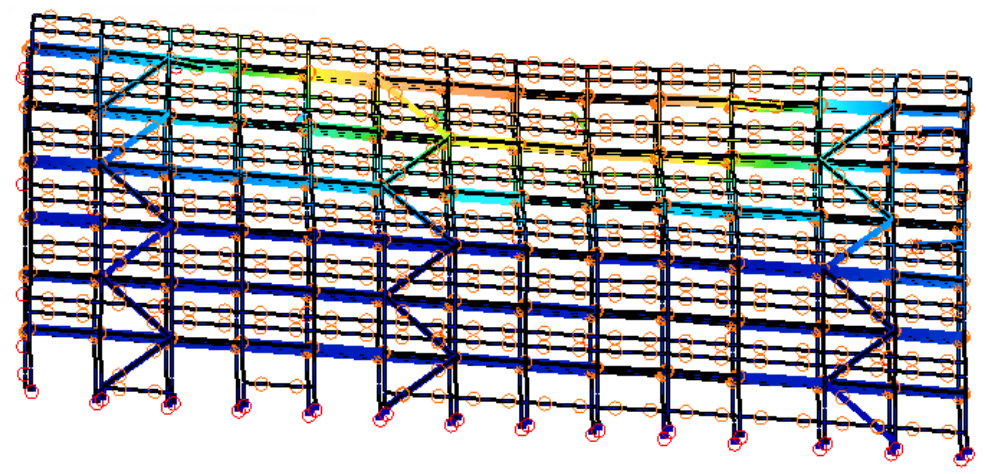

c)

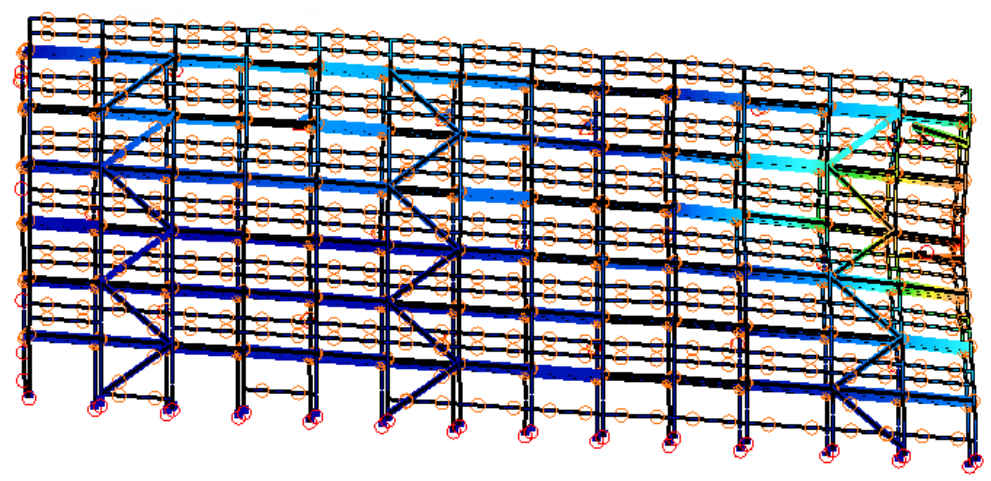

d)

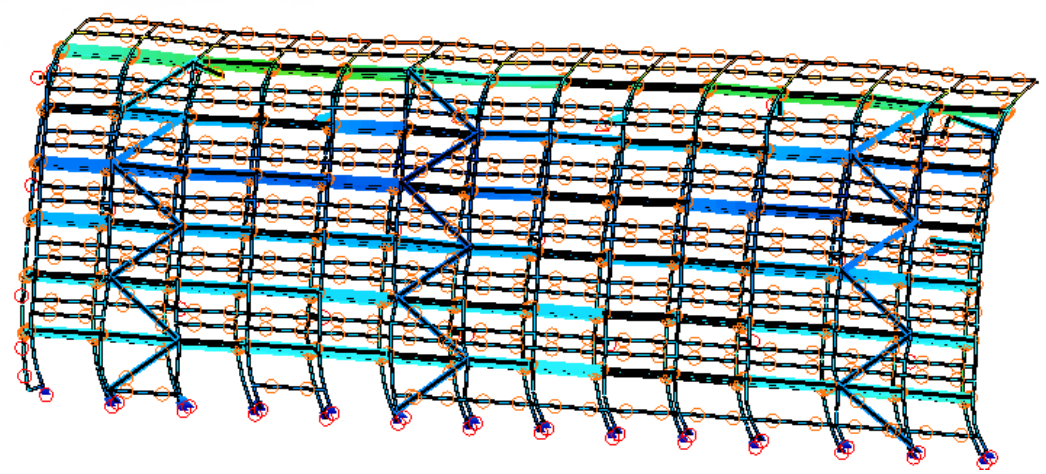

Fig. 5. Mode shapes of the W09 scaffolding: a) $f_{1}=2.3 \mathrm{~Hz}$, b) $f_{2}=4.18 \mathrm{~Hz}$, c) $f_{3}=4.54 \mathrm{~Hz}$, d) $f_{4}=5.04 \mathrm{~Hz}$. 
The weight of scaffolding users can affect the frequency of vibrations, which will be shown on the example of W09 scaffolding. The scaffolding mass is 5.9 tons. The permissible load according to EN 12811-1 [11] according to class 3 is $200 \mathrm{~kg} / \mathrm{m}^{2}$ on one deck level. The total additional mass in case of W09 scaffolding is 4.6 tons, that is $75 \%$ of the scaffolding's mass. Fig. 6 shows how the first four natural frequencies of the W09 scaffolding change with the increase of mass, located at the highest level of decks. Including the mass of users for each scaffolding will result in reduction of the frequency values. However, this change depends on the design of the structure, and in particular the layout of the anchors and braces.

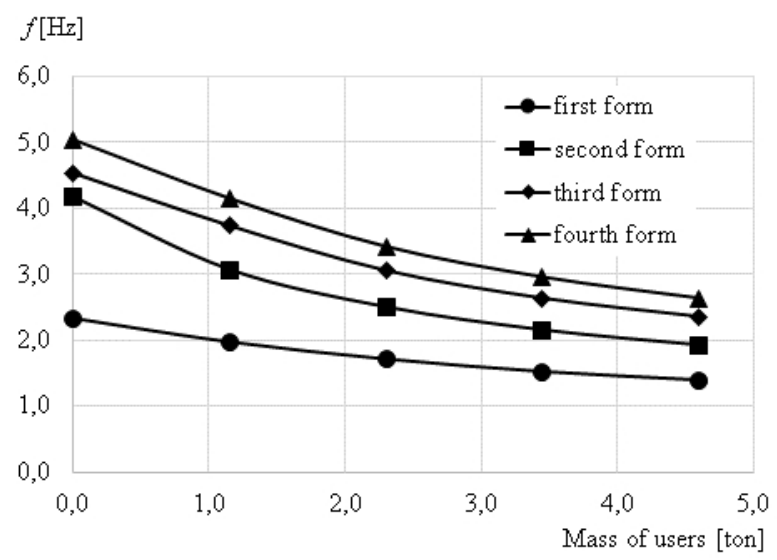

Fig. 6. The influence of users' mass on the natural frequencies of the W09 scaffolding.

\subsection{Damping parameters}

Table 1 summarizes the results of the logarithmic decrement of damping for 30 signals measured on the W09 scaffold. The mean value and standard deviation of the logarithmic decrement of damping are 0.0292 and 0.0088 , respectively. The values determined for several scaffoldings are listed in Table 2. The scaffold symbols used in the table are symbols used in the ORKWIZ project (see [1]).

Table 1. Determination of damping parameters for scaffolding W09

\begin{tabular}{|c|c|c|c|c|}
\hline $\begin{array}{c}\text { Location and } \\
\text { direction of } \\
\text { excitation }\end{array}$ & $\begin{array}{c}\text { Measurement } \\
\text { point and } \\
\text { direction }\end{array}$ & $\begin{array}{c}\text { Damping } \\
\text { coefficient } \gamma \\
{[\mathbf{r a d} / \mathbf{s}]}\end{array}$ & $\begin{array}{c}\text { Frequency of free } \\
\text { vibrations } \boldsymbol{f}_{\boldsymbol{s}} \\
{[\mathrm{Hz}]}\end{array}$ & $\begin{array}{c}\text { Logarithmic } \\
\text { decrement of } \\
\text { damping }\end{array}$ \\
\hline $\mathrm{Ax}$ & $1 \mathrm{x}$ & 0.246 & 2.13 & 0.0184 \\
\hline $\mathrm{Ax}$ & $1 \mathrm{x}$ & 0.228 & 2.13 & 0.0171 \\
\hline $\mathrm{Dx}$ & $1 \mathrm{x}$ & 0.346 & 2.06 & 0.0267 \\
\hline $\mathrm{Dx}$ & $1 \mathrm{x}$ & 0.328 & 2.06 & 0.0253 \\
\hline $\mathrm{Bx}$ & $1 \mathrm{x}$ & 0.436 & 1.94 & 0.0358 \\
\hline $\mathrm{Ex}$ & $1 \mathrm{x}$ & 0.459 & 2 & 0.0365 \\
\hline $\mathrm{Ex}$ & $1 \mathrm{x}$ & 0.634 & 2 & 0.0505 \\
\hline
\end{tabular}




\begin{tabular}{|c|c|c|c|c|}
\hline Fx & $1 x$ & 0.411 & 2 & 0.0327 \\
\hline$A x$ & $2 x$ & 0.244 & 2.13 & 0.0183 \\
\hline$A x$ & $2 x$ & 0.226 & 2.13 & 0.0169 \\
\hline Dx & $2 x$ & 0.345 & 2.06 & 0.0266 \\
\hline Dx & $2 x$ & 0.308 & 2.06 & 0.0238 \\
\hline $\mathrm{Bx}$ & $2 x$ & 0.406 & 2 & 0.0323 \\
\hline $\mathrm{Cx}$ & $2 x$ & 0.414 & 2.06 & 0.0319 \\
\hline $\mathrm{Cx}$ & $2 x$ & 0.432 & 2 & 0.0344 \\
\hline Ex & $2 x$ & 0.302 & 2 & 0.024 \\
\hline Ex & $2 x$ & 0.541 & 2 & 0.0431 \\
\hline Fx & $2 x$ & 0.41 & 2 & 0.0326 \\
\hline Fx & $2 x$ & 0.351 & 1.94 & 0.0288 \\
\hline $\mathrm{Ax}$ & $3 x$ & 0.234 & 2.13 & 0.0175 \\
\hline$A x$ & $3 x$ & 0.232 & 2.13 & 0.0174 \\
\hline Dx & $3 x$ & 0.283 & 2.06 & 0.0218 \\
\hline Dx & $3 x$ & 0.318 & 2.06 & 0.0245 \\
\hline $\mathrm{Bx}$ & $3 x$ & 0.434 & 1.88 & 0.0368 \\
\hline $\mathrm{Cx}$ & $3 x$ & 0.34 & 2.06 & 0.0262 \\
\hline $\mathrm{Cx}$ & $3 x$ & 0.428 & 2 & 0.0341 \\
\hline Ex & $3 x$ & 0.42 & 2 & 0.0334 \\
\hline Ex & $3 x$ & 0.598 & 2 & 0.0476 \\
\hline Fx & $3 x$ & 0.408 & 2 & 0.0325 \\
\hline Fx & $3 x$ & 0.348 & 1.94 & 0.0286 \\
\hline
\end{tabular}

Table. 2. Logarithmic decrement of damping for selected scaffoldings

\begin{tabular}{|c|c|c|c|}
\hline \multirow{2}{*}{$\begin{array}{c}\text { Scaffolding } \\
\text { symbol }\end{array}$} & $\begin{array}{c}\text { First natural frequency } \\
{[\mathrm{Hz}]}\end{array}$ & \multicolumn{2}{|c|}{ Logarithmic decrement of damping } \\
\cline { 3 - 4 } & 2.04 & Mean value & Standard deviation \\
\hline W09 & 3.11 & 0.0292 & 0.0088 \\
\hline P04 & 3.08 & 0.0632 & 0.0133 \\
\hline P05 & & 0.0540 & 0.0156 \\
\hline
\end{tabular}




\begin{tabular}{|l|l|l|l|}
\hline P06 & 3.50 & 0.0571 & 0.0146 \\
\hline P10 & 1.83 & 0.0553 & 0.0119 \\
\hline E05 & 3.10 & 0.0617 & 0.0146 \\
\hline
\end{tabular}

\section{Conclusions}

The first natural frequencies of scaffoldings without users are less than $4 \mathrm{~Hz}$. The first mode shape is usually vibrations along the scaffolding plane, while the second mode shape is in most cases vibrations in the perpendicular horizontal direction.

Due to the low mass of scaffolding structures, the natural frequency of scaffolding with the mass of users included is even lower than the frequencies given in Figure 4. On the other hand, low natural frequencies cause the scaffolds to be susceptible to wind induced vibrations and vibrations generated by the movement of the users at the scaffolding. In the ORKWIZ project, it was found that the movement of the structure is perceptible to the users while walking on the scaffolding, and in work [9] the increase in scaffolding structure effort due to dynamic interactions was confirmed.

Performing dynamic analyzes of scaffolding requires knowledge of damping parameters. For most of the analyzed scaffoldings it can be assumed that the logarithmic decrement of damping for scaffolding is about 0.06. However, for the scaffolding W09 presented here in this paper the calculated value was about 0.03 . In the future it is necessary to determine the damping parameters with more advanced methods. In addition, damping in two directions of vibrations should be investigated.

\section{References}

1. E. Błazik-Borowa, Load and Actions on Scaffoldings as Engineering structures (in Polish) (Lublin University of Technology, Lublin, 2018)

2. M. Pieńko, A. Robak, E. Błazik-Borowa, J. Szer, International Journal of Civil, Environmental, Structural, Construction and Architectural Engineering, 12, 2 (2018)

3. Ł. Borowski, M. Pieńko, P. Wielgos, BGC Geomatics, 8071470 (2017)

4. I. Szer, E. Błazik-Borowa, J. Szer, Arch. Civ. Eng. 3, 63 (2017)

5. M. Jabłoński, I. Szer, J. Szer, JCEM, 24, 6 (2018)

6. T. Lipecki, P. Jamińska-Gadomska, E. Błazik-Borowa, AIP Conf. Proc., 1922 (2018)

7. T. Lipecki, P. Jamińska-Gadomska, A. Sumorek, E. Błazik-Borowa, J. Bęc, JPCS 1101 (2018)

8. H. Bojar, F. Silveira, M. Rebelo, E. Czarnocka, K. Czarnocki, Annals of Agricultural and Environmental Medicine, 100534 (2018)

9. P. Cyniak, E. Błazik-Borowa, J. Szer, T. Lipecki, I. Szer, AIP Conf. Proc., 1922 (2018)

10. P. Jamińska-Gadomska, J. Bęc, T. Lipecki, A. Robak, Arch. Civ. Eng., 64, 1 (2018)

11. EN 12811-1. Temporary structures applied at construction sites. Part 1: Scaffolds. Conditions for development and general principles for designing 